\title{
Efficacy of Praziquantel in Treating Schistosoma Mansoni Infected School Children in Tumuga and Waja, North Ethiopia
}

\author{
Tadesse Dejenie $^{1} *$, Tsehaye Asmelash ${ }^{2}$ and Mahmud Abdelkadir ${ }^{2}$ \\ ${ }^{1}$ Department of Biology, College of Natural and Computational Sciences, Mekelle \\ University, P.O. Box 231, Mekelle, Ethiopia (*taddej2002@gmail.com) \\ ${ }^{2}$ Department of Microbiology, Immunology and Parasitology, College of Health Sciences, \\ Mekelle University, PO Box 1871, Mekelle, Ethiopia
}

\begin{abstract}
Praziquantel (PZQ) is a drug of choice for treating schistosomiasis mansoni. Praziquantel was effectively used to treat schistosomiasis, but there are reports that indicate the appearance of Praziquantel resistance. The objective of this study was to determine the rate of $S$. mansoni infection before and after single treatment, thus to measure the efficacy of Praziquantel in treating Schistosoma mansoni infected individuals in the study area. The study utilized microscopic examination of two Kato-Katz slides for each individual sample before and after treatment. The cure rate of $S$. mansoni infection by Praziquantel in the two study areas remains high and with no significant difference. In Timuga cure rate was $93.44 \%$ and in Waja $88.99 \%\left(\chi^{2}=3.644\right.$ and $\left.\mathrm{P}=0.16\right)$. Efficacy of Praziquantel in treating infections due to $S$. mansoni is still high and there is no evidence for resistance $S$. mansoni against Praziquantel in Tumuga and Waja.
\end{abstract}

Key words: Efficacy, Praziquantel, Schistosomiasis, School children.

\section{INTRODUCTION}

Globally, schistosomiasis is responsible for 500,000 deaths annually (Dupre et al., 1999). The overall prevalence of $S$. mansoni infection in Ethiopia in 225 communities studied between 1979- 1982 was 14\% (Ayele, 1982).

As reduction of schistosomiasis is still beyond human and financial resources, the aim of most control programs remains the reduction of morbidity by treating infected people on an individual or population basis by using chemotherapy agents such as Praziquantel (WHO, 1993). Praziquantel was effectively used to treat schistosomiasis since the last two decades (WHO, 1993; Magnussen, 2003). The treatment of schistosomiasis by Praziquantel requires administration of a single dose $40 \mathrm{mg} / \mathrm{kg}$ of body weight (Engels et al., 2000). As the drug is supplied by a reasonable price in hospitals, still now in Ethiopia, especially in the study area, Praziquantel is the drug of choice in treating schistosome infected individuals.

Praziquantel is a drug of choice for treating schistosomiasis mansoni (Day et al., 1992, Redman et al., 1995). Besides, it has been reported that Praziquantel has shown a remarkable impact in reducing morbidity due to schistosomiasis (WHO, 2000). But there are reports, 
which indicate the occurrence of Praziquantel resistant schistosome strains, which makes the problem of schistosomiasis worse. Low efficacy of Praziquantel in treating human schistosomiasis mansoni was reported in Senegal (Stelma et al., 1995) and Brazil (Katz et al., 1991). Similarly, Follon and Doenhoff (1994) also demonstrated drug resistance of $S$. mansoni for Praziquantel. Similar observation of Praziquantel resistance was also reported by Cioli et al., (1993) and Kasel and Hagan (1999). In vitro, sensitivity test of adult schistosomes showed low response Praziquantel including calcium influx, tegument disruption and muscle contraction (William et al. 2001; Ismail et al., 1999; William and Botros, 2004). Interestingly, there is no report of resistance to multiple treatments by Praziquantel and oxamniquine (Follon and Doenhoff, 1994).

The occurrence of Praziquantel resistant schistosomes is a potential problem to control schistosomiasis. Thus, such survey was designed to test whether there are Praziquantel resistant schistosomes in Tigray or not. In this study, determination of the rate of S. mansoni infection before and after single treatment was performed to measure the efficacy of Praziquantel in the treatment of $S$. mansoni infected individuals.

The outcome of the study will have important implications for schistosomiasis control. Therefore, from the outcome of the study a clear recommendation in treatment of schistosomiasis will be given, that is by praziquantel alone or by mixed treatment with that of oxamniquine. But treating individuals by mixed treatment without having the information of resistance history costs unnecessary expense. The information that will be gained might provide baseline data for designing suitable and cost effective control scheme against schistosomiasis mansoni in our country. Besides, the study may be helpful to the understanding of the current status efficacy status of praziquantel in Ethiopia.

\section{MATERIALS AND METHODS}

The study was done in two towns in the southern tip of Tigray Regional State (northern Ethiopia); Timuga and Waja, $190 \mathrm{~km}$ and $195 \mathrm{~km}$, respectively far to the south from the capital city of the region, Mekelle. The two cities were selected purposely based on previous schistosomiasis mansoni prevalence rate of $87 \%$ in Timuga (Tadesse and Beyene, 2009) and $36.4 \%$ in Waja (Tadesse et al., 2009). In this study, schoolchildren were used to index the assessment of community prevalence (Guyatt et al., 1999).

Sample size (n) was determined using the statistical formula $p(1-p) z^{2} / d^{2}$ (Daniel, 1995). The overall prevalence rate (p) of S. mansoni in the study area was determined to be $61.7 \%$ from the previous studies in the same study area; p was taken to be $61.7 \%$ (Tadesse et al., (C) CNCS 
2009; Tadesse and Beyene 2009). For the calculation, a 95\% confidence interval (z) and a 5\% margin of error (d) were used. This gave a sample size of 364. Besides, to minimize errors arising from the likelihood of non compliance, seven percent of the sample size was added to the normal sample $(364+26=390)$. Thus, a total of 390 schoolchildren (152 females and 238 males) were selected from Waja (172) and Tumuga (218) Primary schools. The subjects were selected randomly from their grade categories. The study utilized examination of Kato-Katz slides (42.7 mg stool/slide) for each individual (Peters et al., 1980). Four weeks after the first treatment, the treated patients were tested again, using two Kato-Katz slides for each individual. First samples (before treatment) data was collected in March 2009, while the second samples (after treatment) was undertaken in February 2009. Those individuals who do not pass ova were subsequently excluded. Here, the state of no cure was determined by the presence of ova of $S$. mansoni in the stool specimen.

All patients with positive fecal smears were treated with the standard dose of Praziquantel (40 $\mathrm{mg} / \mathrm{kg}$ body weight, single dose) under the supervision of the authors. Specimens were collected on-the-spot and transported to Parasitology laboratory of the Department of Biology at Mekelle University for microscopic examination. For each stool sample, two slides were prepared and microscopically examined by well trained expertise to detect $S$. mansoni eggs. The data collected was entered in to SPSS program version 12 and were analyzed by using appropriate statistical packages (percentile and Chi-square test).

\section{RESULTS AND DISCUSSION}

\subsection{Prevalence of $S$. mansoni}

The prevalence of Schistosoma mansoni in both study areas Tumuga and Waja was $63.3 \%$ and $73.84 \%$, respectively (Table 1 ). The average prevalence of schistosomiasis mansoni in both study areas was $67.95 \%$. This average is done because the old town Waja on the south direction and the new town Tumuga on the north direction are divided by A Waja Wuha River. When compared with previous studies in Tumuga (Author, 2009), the prevalence of $S$. mansoni infection was $87 \%$, thus in this report the infection reduces by $27.7 \%$ (Tadesse and Beyene, 2009). On the other hand $31.95 \%$ increase in prevalence was recorded in Waja in the current survey (Tadesse et al., 2009). We have no evidence for showing neither environmental modification nor educational programs that could show behavioral changes of school children of Tumuga to water contact. Similarly, we cannot demonstrate for the increase in prevalence of S. mansoni infection prevalence in Waja. For this reason, it is 
difficult to say infection decrease or increase because children share the same water source (Waja Wuha) that acts as a source of S. mansoni infection.

\subsection{Pretreatment Results}

Similar proportion of the age dependent prevalence of S. mansoni infection was demonstrated in both before and after infection (Fig. 1). The highly affected age groups were 10-14 and 1519 year old and the least affected age groups were 5-9 and 20-24 $\left(\chi^{2}=12.3, \mathrm{P}<0.05\right)$. Similar findings were reported in the same study sites and elsewhere in Ethiopia (Berhanu, 1988; Hailu et al., 1997; Alemayehu et al., 1998; Tadesse and Beyene, 2009)

Table 1. Prevalence of S. mansoni infection in Tumuga and Waja Primary Schools, examined in February 2009

\begin{tabular}{|lrrr|}
\hline School & \# examined & \# Positive & \%Prevalence \\
\hline Tumuga & 218 & 138 & 63.30 \\
\hline Waja & 172 & 127 & 73.84 \\
\hline Total & 390 & 265 & 67.95 \\
\hline
\end{tabular}

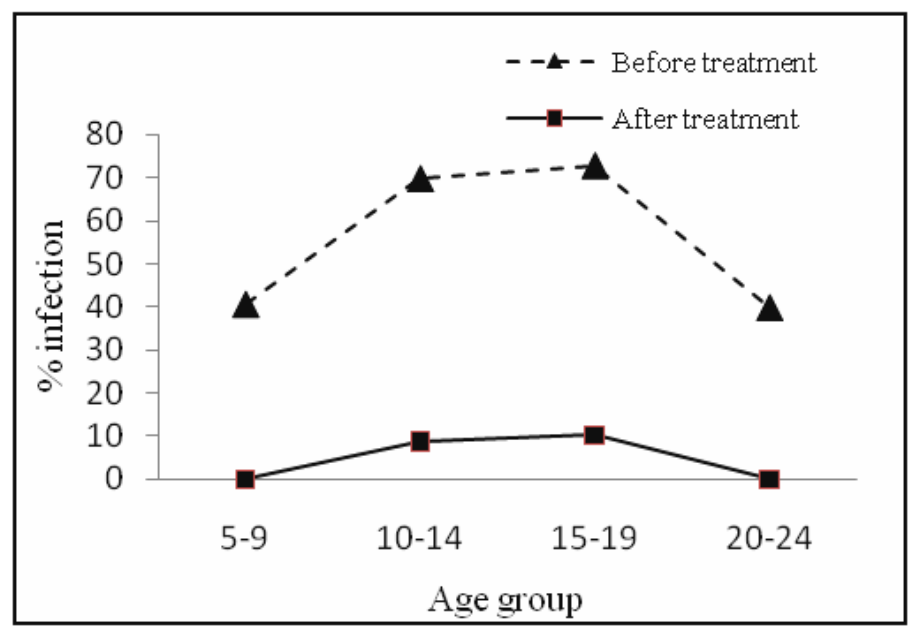

Figure 1. Percentage of $S$. mansoni infection before and after treatment with Praziquantel in Tumuga and Waja Primary Schools, examined in February and March 2009.

\subsection{Post treatment results}

The cure rate after one treatment with the standard dose of $40 \mathrm{mg} / \mathrm{kg}$ PZQ was $84.5 \%$, ranging from 73.8 to $92.3 \%$ in the individual primary schools (Table 2). Infection before and after treatment was highly significant (Fig. 2) $\left(\chi^{2}=15.66\right.$ and $\left.\mathrm{P}=0.000\right)$ but cure rate among sexes remains in similar proportion $(\mathrm{p}>0.05)$. The results of the present study indicated that there is no sex difference in S. mansoni infection in both pre- and post-treatment tests. This findings agree with previous works by the same authors in the study sites (Tadesse and (C) CNCS 
Beyene, 2009) Such findings indicate that there is no S. mansoni infection difference between male and female sexes, and also confirmed the efficacy of PZQ has no sex bias.

Table 2. Single dose Praziquantel treatment result of S. mansoni infected School Children in Tumuga and Waja, examined in March 2009.

\begin{tabular}{|lccccc|}
\hline School & $\begin{array}{l}\text { \# } \\
\text { treated }\end{array}$ & $\begin{array}{c}\text { \# absent or } \\
\text { not volunteer }\end{array}$ & $\begin{array}{l}\text { Examined } \\
\text { Examed }\end{array}$ & $\begin{array}{l}\text { \# } \\
\text { cured }\end{array}$ & $\begin{array}{c}\text { \% } \\
\text { Cure }\end{array}$ \\
\hline Tumuga & 138 & 16 & 122 & 114 & 93.44 \\
\hline Waja & 127 & 18 & 109 & 97 & 88.99 \\
\hline Total & 265 & 40 & 225 & 205 & 91.11 \\
\hline
\end{tabular}

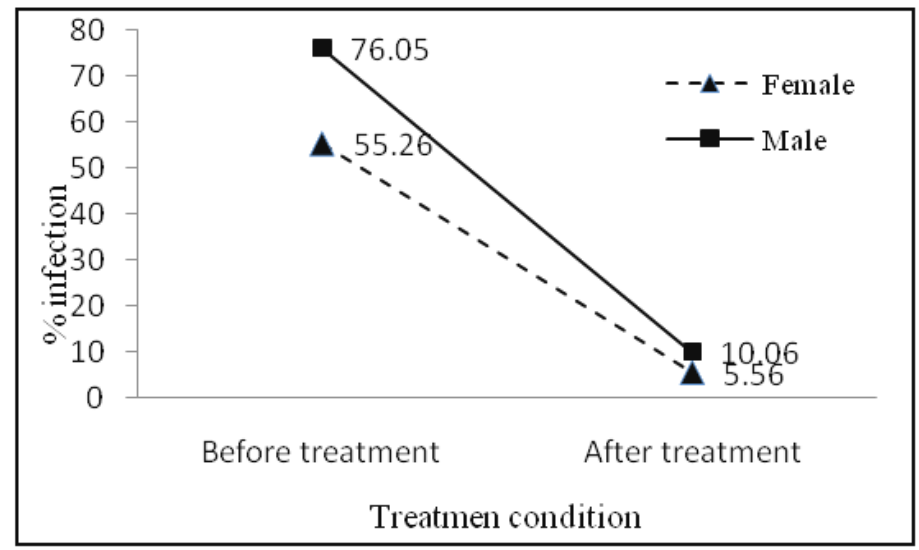

Figure 2 Percentage of infection among sexes before and after treatment in Tumuga and Waja Primary Schools, in February and March 2009.

Table 3. Intensity of S. mansoni infection before and after Praziquantel single treatment in Timuga and Waja School Children, 2009.

\begin{tabular}{|r|r|r|r|}
\hline \multirow{2}{*}{ Treatment } & \multicolumn{3}{|c|}{ Intensity } \\
\cline { 2 - 4 } & \multicolumn{1}{|l|}{ Low } & \multicolumn{1}{|c|}{ Medium } & Heavy \\
\hline Pre-treatment & $135(50.94 \%)$ & $102(38.49 \%)$ & $28(10.57 \%)$ \\
\hline Post-treatment & $13(65 \%)$ & $6(30 \%)$ & $1(5 \%)$ \\
\hline
\end{tabular}

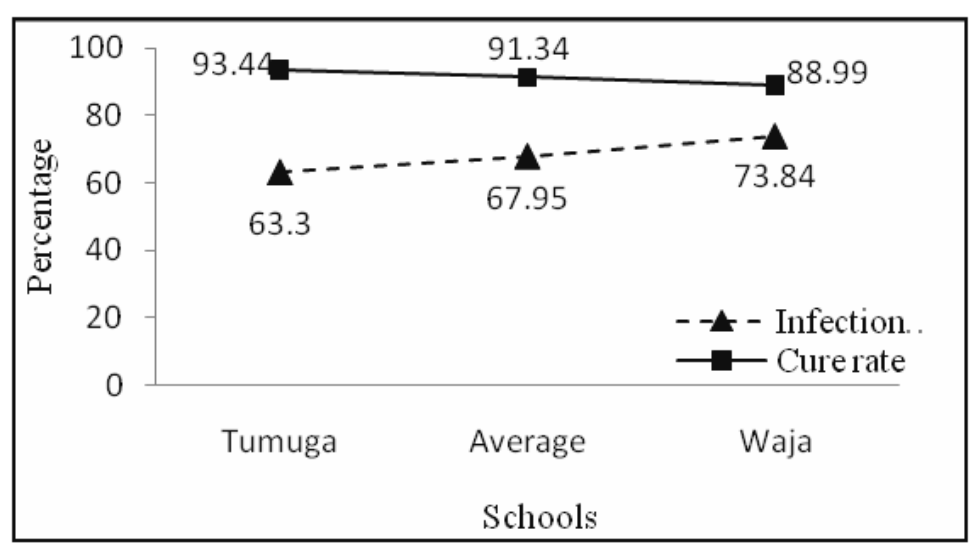

Figure 3. Percentage of infection (before treatment) and cure rate after treatment with Praziquantel in Tumuga and Waja, in February and March 2009. 
The cure rate of $S$. mansoni infection by Praziquantel in the two study areas remains the same, in Timuga cure rate was $93.44 \%$ and with that of Waja it was $88.99 \%$ (Fig. 3$)\left(\chi^{2}=\right.$ 3.644 and $\mathrm{P}>0.15)$.

In the current study, intensity of medium and heavy infection after single treatment reduced from $38.49 \%$ to $30 \%$ and from $10.57 \%$ to $5 \%$, respectively (see Table 3 ). Infections after Praziquantel treatment remain light infection (Botrosa et al., 2005).

Cure rate after single treatment with Praziquantel reported in this study (88.99-93.44\%) was found to be similar and in a range of previously reported efficacy of Praziquantel against Schistosoma infection (70-95\%) in Ethiopia (Getnet et al., 2002) and outside Ethiopia (Barakat, 2000; Botrosa et al., 2005).

\section{CONCLUSION}

Prevalence of S. mansoni infection was not reduced in Waja and Timuga. Efficacy of Praziquantel in treating infections due to $S$. mansoni is still high and there is no evidence for resistance S. mansoni against Praziquantel in Tumuga and Waja. Thus, authors recommend that treating schistosomiasis patents with Praziquantel in the study aria is still efficient and coast effective.

\section{ACKNOWLEDGEMENT}

This study was financially supported by the Mekelle University Inter University Cooperation project (MU-IUC). We would also like to acknowledge Dawit Gebre-egziabher, Getachew Mengistu and Selam Negussie,, who actively participated in data collection and microscopic examination. Our thanks also goes to Timuga and Waja Primary School directors, teachers and students. This study would not be materialized without the assent and willingness of the study participants.

\section{REFERENCES}

Alemayehu, T., Ye-ebiyo, Y., Ghebreyesus, T. A \& Wtten, K. H. 1998. Malaria, Schistosomiasis, and intestinal helminths in relation to micro-dams in Tigray, northern Ethiopia. Parassitologia, 40: 259-267.

Ayele, T. 1982. The distribution of Schistosomiasis in Ethiopia: results of 1978-1982 Survey. Ayele, T. and Lo, C. T. (eds.), Proceed Symp Human Schist, Addis Ababa. 
Barakat, R., Farghaly, A., El Masry, A.G., El-Sayed, M.K \& Hussein, M.H. 2000. The epidemiology of schistosomiasis in Egypt: patterns of Schistosoma mansoni infection and morbidity in Kafer El-Sheikh. Am. J. Trop. Med. Hyg. 62: 21-27.

Berhanu Erko, 1988. Epidemiology of schistosomiasis in Bahar Dar, M. Sc. Thesis, Addis Ababa University, pp. 60-67(Unpubl).

Botrosa, S., Sayeda, H., Amera, N., El-Ghannama, M., Bennettb, J.L \& Dayb, T.A. 2005. Current status of sensitivity to praziquantel in a focus of potential drug resistance in Egypt. International Journal for Parasitology, 35: 787-791.

Cioli, D., Pica-Mattocci, L \& Archer, S. 1993. Drug resistance in schistosomes. Parasitol Today, 9: 162-166.

Day, T. A., Bennett, J. L \& Pax, R. A. 1992. Praziquantel: an enigmatic anti-parasitic. Parasitol Today, 8: 342-344.

Daniel, W.W. 1995. Biostatistics a foundation for analysis in the health science. 6th ed. New York: John Willey \& Sons Inc, New York, USA, 155pp.

Dorit, R.L, Walker, W.F \& Barner, R.D. (1991) Zoology. Tokyo, Sounders College publishing. Toronto London Sydney, 632pp.

Engels, D., Chitsulo, L., Montresor, A \& Savioli, L. 2002. The global epidemiological situation of schistosomiasis and new approaches to control and research. Acta Trop., 82:139-146.

Fallon, P. G \& Doenhoff, M. J. 1994. Drug-resistant in schistosomiasis: resistance to praziquantel and oxamniquine induced in S. Mansoni in mice is drug specific. Am. J. Trop. Med. Hyg., 29 (2):217- 219.

Getnet Degu, Getahun Mengistu \& Jones, J. 2002. Praziquantel efficacy against schistosomiasis mansoni in schoolchildren in north-west Ethiopia. Trans. R. Soc. Trop. Med. Hyg., 96: 444-445.

Guyatt, H.L., Brooker, S \& Donnelly, C. A. 1999. Can prevalence of infection in school aged children be used as an index for assessing community prevalence? Parasitology, 51: 83-88.

Hailu Birrie, Medhin, G., Erko, B., Beshah, G \& Gemechu, T. 1997. Intestinal helminth infections among the current residents of the future Finchaa Sugar plantation area, Western Ethiopia. Ethiop. J. Health Dev., 11: 219-228. 
Ismail, M., Botros, S., Metwally, A., William, S., Farghally, A., Tao, L.F., Day, T.A \& Bennett, J.L. 1999. Resistance to praziquantel: direct evidence from Schistosoma mansoni isolated from Egyptian villagers. Am. J. Trop. Med. Hyg., 60: 932-935.

Kataz, N., Rocha, R. S., De Soza, C. P., Filho, P. C., Bruce, J. I., Coles, G. C \& Kinoti, G. K. 1999. Efficacy of alternating therapy with oxamiquine and praziquantel to treat $S$. mansoni in children following failure of first treatment. Am. J. Trop. Med. Hyg., 44: 509-512.

Kusel, J \& Hagan, I. 1999. Praziquantel-its use, cost and possible development of resistance. Parasitology Today, 15: 352-354.

Lo, C.T., Kloos, H \& Hailu, B. 1988. Schistosomiasis. In: Zein Ahmed and Kloos, H. (eds.), The Ecology of Health and Disease in Ethiopia, Addis Ababa: EMPDA Press, 196207.

Magnussen, P. 2003. Treatment and re-treatment strategies for schistosomiasis control in different epidemiological settings: a review of 10 years' experiences. Acta Trop., 86: $243-254$.

Peters, P.A., Alamy, M.E., Warren, K.S \& Mahmoud, A.A.F. 1980. Quick Kato Smear for field quantification of Schistosoma mansoni eggs. Am. J. Trop. Med. Hyg., 29 (2): 217- 219.

Reedman, C. A. 1995. Praziquantel: an urgent and exiting challenge. Parasitol. Today, 12: $14-20$.

Rozendaal, J .R. 1997. Vector Control Methods for use by Individuals and Communities. WHO, Genva, pp.337- 356.

Ruppert, E.E \& Barnes, R.D. 1994. Invertebrate Zoology. $6^{\text {th }}$ edition. Sounders college Publishing, Toronto, 245pp.

Smith, D.H., Warren, K.S \& Mahmoud. A.F. 1979. Morbidity in schistosomiasis mansoni in relation to intensity of infection: study of a community in kisumu, Kenya. Am. J. Trop. Hyg., 28: 220-229.

Stelma, F. F., Talla, I, Sow, S., Kongs, A., Niang, M., Polman, K., Deelder, A. M \& Gryseels, B. 1995. Efficacy and side effects of Praziquantel in an epidemic focus of Schistosoma mansoni. Am. J. Trop. Med. Hyg., 53: 167-170.

Tadesse Dejenie \& Beyene Petros. 2009. Irrigation Practices and Intestinal Helminth Infections in Southern and Central Zones of Tigray. Ethiop.J.Health Dev., 23(1): 48- 56. 
Tadesse Dejenie, Tsehaye Asmelash \& Mekonnen Teferi. 2009. Intestinal Helminthes Infections and Re-Infections with Special Emphasis on Schistosomiasis Mansoni in Waja, North Ethiopia. Momona Ethiopian Journal of Science, 2 (1): 4-16.

WHO. 1993. Control of Schistosomiasis; Second report of WHO expert committee. WHO Tech.Rep.ser.830. Geneva.

WHO. 2000. Report of the WHO informal consultation on schistosomiasis in low transmission areas: control strategies and criteria for elimination. WHO, London.

William, S \& Botros, S. 2004. Validation of sensitivity to praziquantel using Schistosoma mansoni worm muscle tension and $\mathrm{Ca} 2 \mathrm{C}$-uptake as possible in vitro correlates to in vivo ED50 determination. Int. J. Parasitol., 34: 971-977.

William, S., Botros, S., Ismail, M., Farghally, A., Day, T.A \& Bennett, J.L. 2001. Praziquantel-induced tegumental damage in vitro is diminished in schistosomes derived from praziquantel-resistant infections. Parasitology, 122: 63-66. 